\title{
Simulation of the Azov Sea Water Circulation Subject to the River Discharge
}

\author{
V.V. Fomin ${ }^{1}$, A.A. Polozok ${ }^{2}$, I.N. Fomina ${ }^{2}$ \\ ${ }^{1}$ Marine Hydrophysical Institute, Russian Academy of Sciences, Sevastopol, \\ Russian Federation \\ e-mail:v.fomin@ukr.net \\ ${ }^{2}$ Sevastopol Branch of the Zubov State Oceanographic Institute, Sevastopol, \\ Russian Federation
}

\begin{abstract}
Features of river water distribution in the Sea of Azov are studied and the estimates of river flows' velocities are obtained based on the $\sigma$-coordinate numerical baroclinic model. The model is realized in the grid with $1400 \mathrm{~m}$ horizontal resolution. In $\sigma$-coordinate 15 equally spaced levels were used. Time integration was performed with 2 min step. The computational domain consisted of the Azov Sea, the Kerch Strait and the Black Sea north-eastern shelf. It is shown that river flows represent an alongshore cyclonic-directed jet encircling the Sea of Azov and flowing to the Kerch Strait. Velocity of the currents in the jet was $0.03-0.05 \mathrm{~m} / \mathrm{s}$. The complexity of the coastline and bottom topography configuration leads to a jet meandering and formation of local vortex structures. Evolution of the Azov Sea currents and thermohaline structure is modeled for the period of the intense storm in November, 2007. Climatic temperature and salinity distributions are used as the initial fields. The following areas are found to be the most dynamically active: the frontal zone in the Taganrog Bay (due to the Don discharge); the salt water zone in the southern part of the Azov Sea (related to penetration of the Black Sea waters); two local zones of seawater freshening nearly the Kuban branches.
\end{abstract}

Keywords: the Azov Sea, $\sigma$-coordinate model, baroclinic circulation, river outlets, salinity fields, vortex structures.

DOI: 10.22449/1573-160X-2015-1-15-26

(c) 2015, V.V. Fomin, A.A. Polozok, I.N. Fomina

(C) 2015, Physical Oceanography

Introduction. Due to the Azov Sea shallowness wind effects make a decisive contribution to its dynamics. Meanwhile the influence of the density of water gradients on water circulation takes place only in the frontal areas near the estuaries of rivers and straits. For the calculation of dynamic processes in the Azov Sea the barotropic models are usually used.

At the same time there is a number of important problems, where the water density structure records are principled. These include: modeling of river water propagation and transformation into the sea and formation of the frontal salinity zones; the water thermohaline structure reaction on the intense atmospheric effects; calculation of water desalination and salinization scenarios.

In [1] the methodological aspects of the numerical simulation of frontal zones in the simplest form basins are studied. Being its continuation, the present article aims to research the spread of the Don River and the Kuban water over the Azov Sea water area; to analyse the response of fields of currents and the Azov Sea water salinity to the real situation of the intense storm in November 2007.

The TVD-schemes applied [5] numerical hydrodynamic model [1 -4] is used to solve the aforementioned problems. These schemes are second order approximations and have the property of monotonicity of numerical solutions. It should be noted that this feature of difference schemes is a necessary condition for an adequate simulation of high-gradient fields of currents, sea water temperature and salinity. 
The problem mathematical formulation and solution method. The source is 3-dimensional $\sigma$-coordinate ocean thermohydrodynamics equations in the Boussinesq approximation and the type hydrostatics. (here and further summation over repeated $\alpha$ and $\beta(1-2)$ indices is suggested) [3]:

$$
\begin{gathered}
\frac{\partial}{\partial t}\left(D u_{\alpha}\right)+\Lambda u_{\alpha}+\varepsilon_{\alpha \beta} f D u_{\beta}+g D \frac{\partial \eta}{\partial x_{\alpha}}+D G_{\alpha}= \\
=\frac{\partial}{\partial x_{\beta}}\left(D \tau_{\alpha \beta}\right)+\frac{\partial}{\partial \sigma}\left(\frac{K_{m}}{D} \frac{\partial u_{\alpha}}{\partial \sigma}\right) \\
\frac{\partial \eta}{\partial t}+\frac{\partial}{\partial x_{\alpha}}\left(D u_{\alpha}\right)+\frac{\partial w}{\partial \sigma}=0 \\
\frac{\partial}{\partial t}(D T)+\Lambda T=\frac{\partial}{\partial x_{\beta}}\left(A_{c} \frac{\partial T}{\partial x_{\beta}}\right)+\frac{\partial}{\partial \sigma}\left(\frac{K_{c}}{D} \frac{\partial T}{\partial \sigma}\right) \\
\frac{\partial}{\partial t}(D S)+\Lambda S=\frac{\partial}{\partial x_{\beta}}\left(A_{c} \frac{\partial S}{\partial x_{\beta}}\right)+\frac{\partial}{\partial \sigma}\left(\frac{K_{c}}{D} \frac{\partial S}{\partial \sigma}\right) \\
\rho=\rho(T, S), \\
G_{\alpha}=\frac{1}{\rho_{0}} \frac{\partial p_{A}}{\partial x_{\alpha}}+\frac{g}{\rho_{0}}\left(\frac{\partial}{\partial x_{\alpha}} D \int_{\sigma} \rho\left(\sigma^{\prime}\right) d \sigma^{\prime}+\sigma \frac{\partial D}{\partial x_{\alpha}} \rho\right) \\
\Lambda \varphi=\frac{\partial}{\partial x_{\beta}}\left(D u_{\beta} \varphi\right)+\frac{\partial}{\partial \sigma}(w \varphi), \quad \tau_{\alpha \alpha}=2 A_{m} \frac{\partial u_{\alpha}}{\partial x_{\alpha}}, \quad \tau_{\alpha \beta}=\tau_{\beta \alpha}=A_{m}\left(\frac{\partial u_{\beta}}{\partial x_{\alpha}}+\frac{\partial u_{\alpha}}{\partial x_{\beta}}\right)
\end{gathered}
$$

where $t$ is time; horizontal axes $\left(x_{1}, x_{2}\right)$ respectively oriented to the east and north; $\sigma$ is the vertical dimensionless coordinate, which varies from -1 to 0 and is directed vertically upward; the following unknown variables: $\eta$ is the sea freesurface coordinate; $u_{1}, u_{2}$ are the zonal and meridional components of currents velocity; $w$ is the $\sigma=$ const surface normal component current velocity; T, $S, \rho$ are the sea water temperature, salinity and density.

The other variables (1) - (5) of the system have the following meaning: $D=h+\eta$ is the basin dynamic depth; $h$ is the bottom contour; $p_{A}$ is the atmospheric pressure; $\tau_{\alpha \beta}$ is the turbulent stress tensor components; $A_{m}, A_{c}$ and $K_{m}, K_{c}$ are the coefficients of horizontal and vertical turbulent viscosity and diffusion, respectively; $g$ is the gravitational acceleration; $f$ is the Coriolis parameter; $\varepsilon_{\alpha \beta}=0$ when $\alpha=\beta ; \varepsilon_{12}=-1 ; \varepsilon_{21}=1$.

On the free surface ( $\sigma=0$ ) there are the following desired conditions:

$$
w=0, \quad \frac{K_{m}}{D} \frac{\partial u_{\alpha}}{\partial \sigma}=\frac{\tau_{\alpha}^{0}}{\rho_{0}},
$$




$$
\frac{K_{c}}{D} \frac{\partial T}{\partial \sigma}=\frac{Q_{T}}{\rho_{0} c_{p}}, \frac{K_{c}}{D} \frac{\partial S}{\partial \sigma}=\frac{Q_{S}}{\rho_{0}},
$$

here $\tau_{\alpha}^{0}=\left(\tau_{1}^{0}, \tau_{2}^{0}\right)$ are the surface tangential wind stress projections; $Q_{T}, Q_{S}$ are the heat and salts fluxes through the basin free surface; $c_{p}$ is the specific water heat capacity. The components $\tau_{\alpha}^{0}$ are determined by the following expressions:

$$
\tau_{1}^{0}=\rho_{a} C_{a}|W| W_{1}, \quad \tau_{2}^{0}=\rho_{a} C_{a}|W| W_{2},
$$

where $\rho_{a}$ is the air density; $C_{a}$ is the surface friction coefficient; $|W|, W_{1}, W_{2}$ are the wind speed module and components at $10 \mathrm{~m}$ above the sea level.

Boundary conditions at the bottom $(\sigma=-1)$ are expressed as follows:

$$
\begin{array}{r}
w=0, \quad \frac{K_{m}}{D} \frac{\partial u_{\alpha}}{\partial \sigma}=C_{b}|u| u_{\alpha}, \\
\frac{K_{c}}{D} \frac{\partial T}{\partial \sigma}=0, \quad \frac{K_{c}}{D} \frac{\partial S}{\partial \sigma}=0,
\end{array}
$$

where $|u|$ is the module of the horizontal current speed; $C_{b}=\kappa^{2} / \ln \left(\delta z / z_{b}\right)^{2}$ is the near-bottom friction coefficient; $\kappa=0,4$ is the Karman's constant; $\delta z$ is the vertical distance from the bottom up to the point at which the friction coefficient is determined; $z_{b}$ is the bottom surface roughness parameter.

On the hard side boundaries, the "sticking" conditions for the horizontal components of the speed and conditions of zero fluxes for temperature and salinity are specified. On the liquid boundaries the free passage terms (see below) are used. At the river outlet discharge $Q_{r}$, its temperature and salinity $T_{r}$ and $S_{r}$ are known.

The detailed description of the system solution numerical algorithm (1) - (5) is given in [3]. Vertical turbulent viscosity and diffusion coefficients $K_{m}$ and $K_{c}$ are determined based on the Mellor - Yamada theory [6].

The model is realized in the grid with $\sim 1400 \mathrm{~m}$ horizontal resolution. In $\sigma$-coordinate 15 equally spaced levels were used. Time integration was performed with 2 min step. The computational domain consisted of the Azov Sea, the Kerch Strait and the Black Sea north-eastern shelf (Fig. 1).

As the southern liquid boundary, the latitudinal section Cape Meganom - Cape Utrish was selected. Here the conditions for the free passage of the meridional component of the velocity of currents and conditions of the "smooth continuation" for temperature and salinity were set:

$$
\bar{u}_{2}=\sqrt{\frac{g}{h}} \eta, \quad \frac{\partial u_{2}}{\partial t}+c_{f} \frac{\partial u_{2}}{\partial y}=0, \quad \frac{\partial T}{\partial y}=0, \quad \frac{\partial S}{\partial y}=0,
$$

where $\bar{u}_{2}$ is the depth mean meridional velocity component; $c_{f}$ is the phase velocity of the perturbation velocity near the boundary, estimated by the previously 
known time step values $u_{2}$. Computational domain expansion to the south is made to reduce the impact of liquid boundaries on the numerical solution for the Kerch Strait.

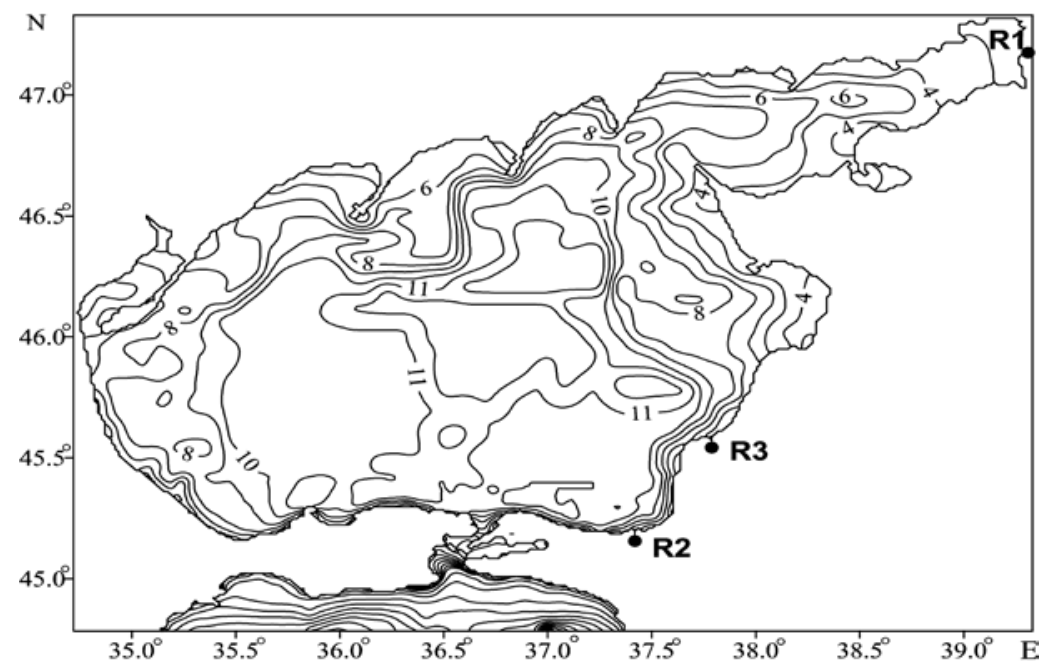

Fig. 1. Model bottom contour (m) of the Azov Sea (position of the riverbeds: R1 - the Don, R2 - the Kuban branch, R3 - the Protok branch)

Previously [3] used model was verified according to the level of marine hydrometeorological observation stations (HMS). We use the hourly level measurements by recorders on HMS Henichesk and HMS Mariupol and tide gauge measurements every 6 hours at HMS Berdyansk and HMS Mysovoe. A comparison of model and field data is presented in Fig. $2-5$.

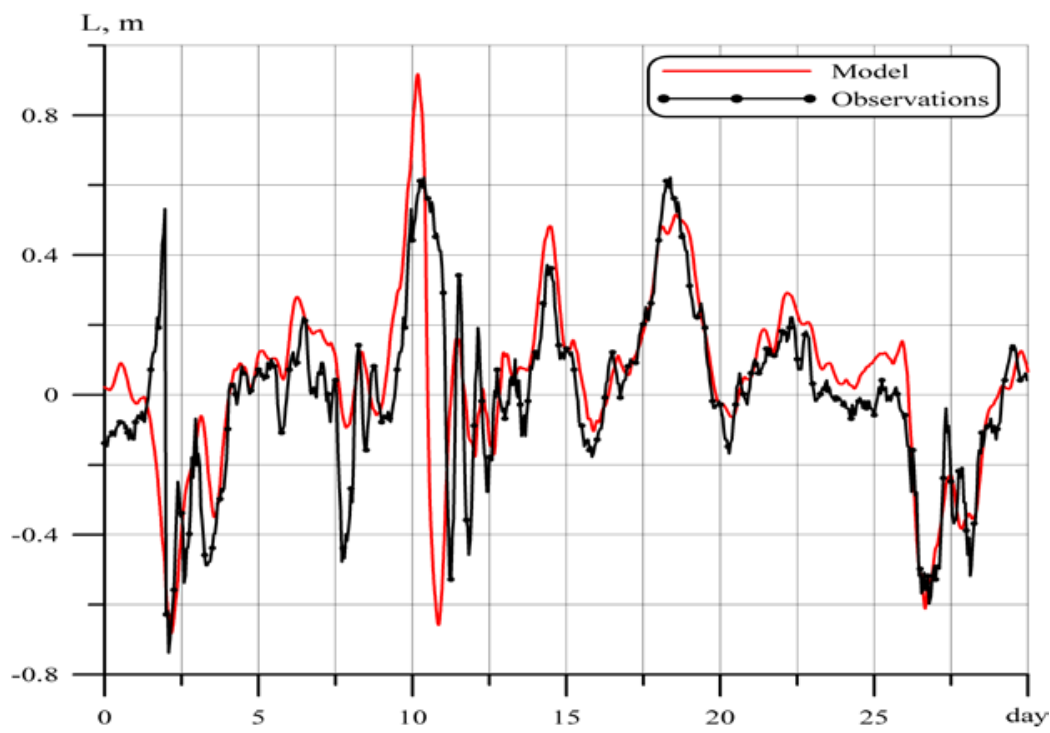

Fig. 2. The Azov Sea level (m) variations at HMS Genichesk in November 2007 


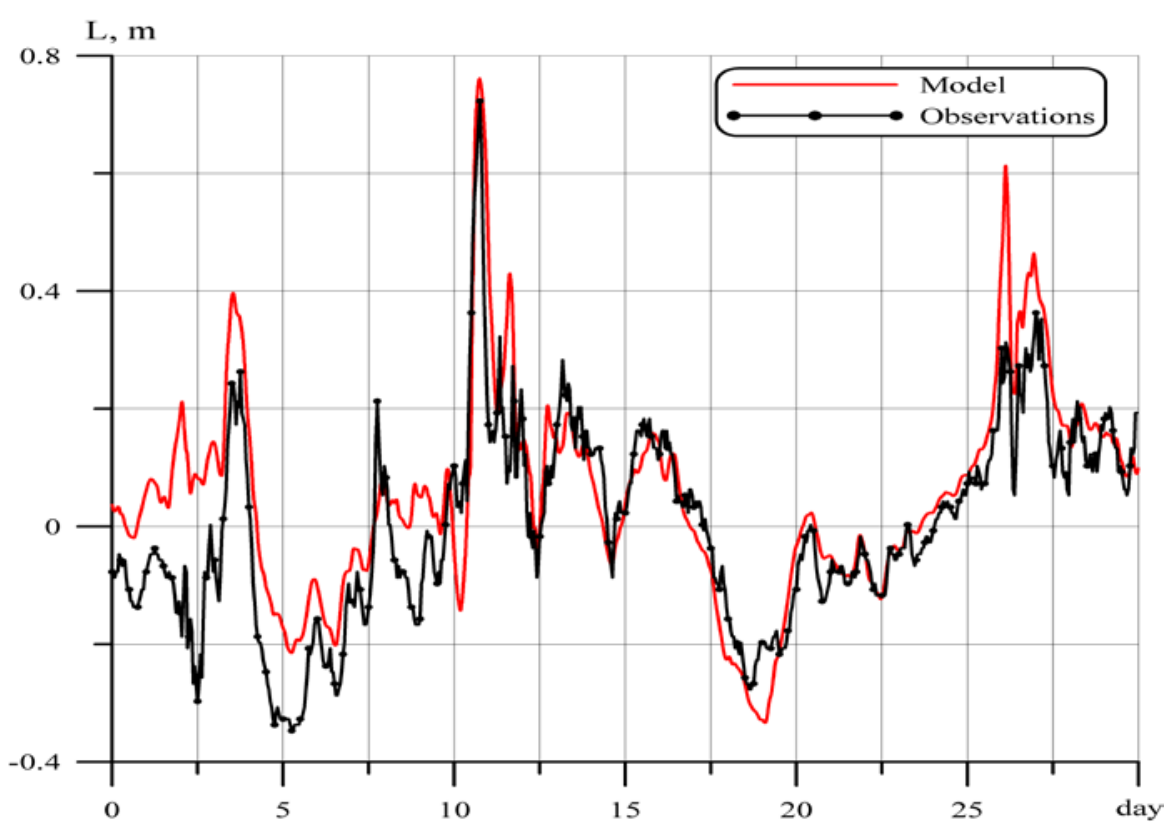

Fig. 3. The Azov Sea level (m) variations at HMS Mariupol in November 2007

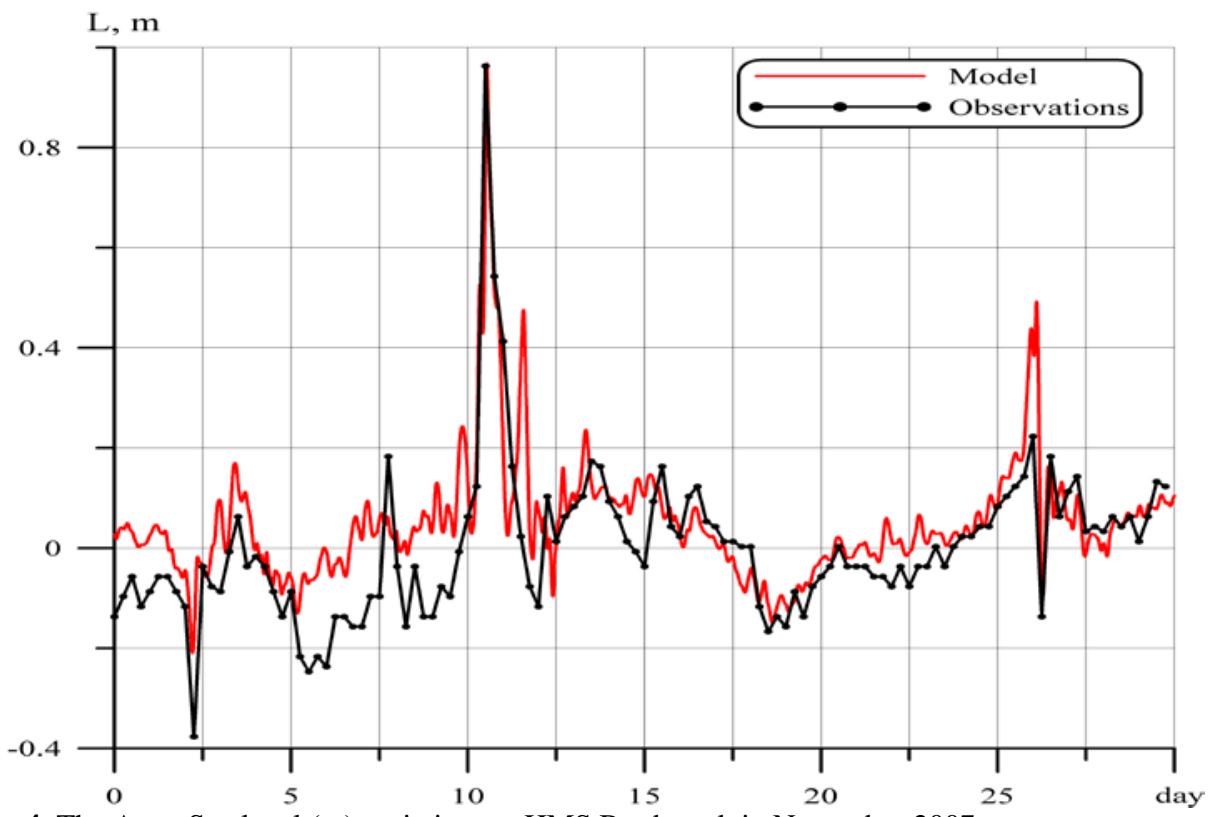

Fig. 4. The Azov Sea level (m) variations at HMS Berdyansk in November 2007 


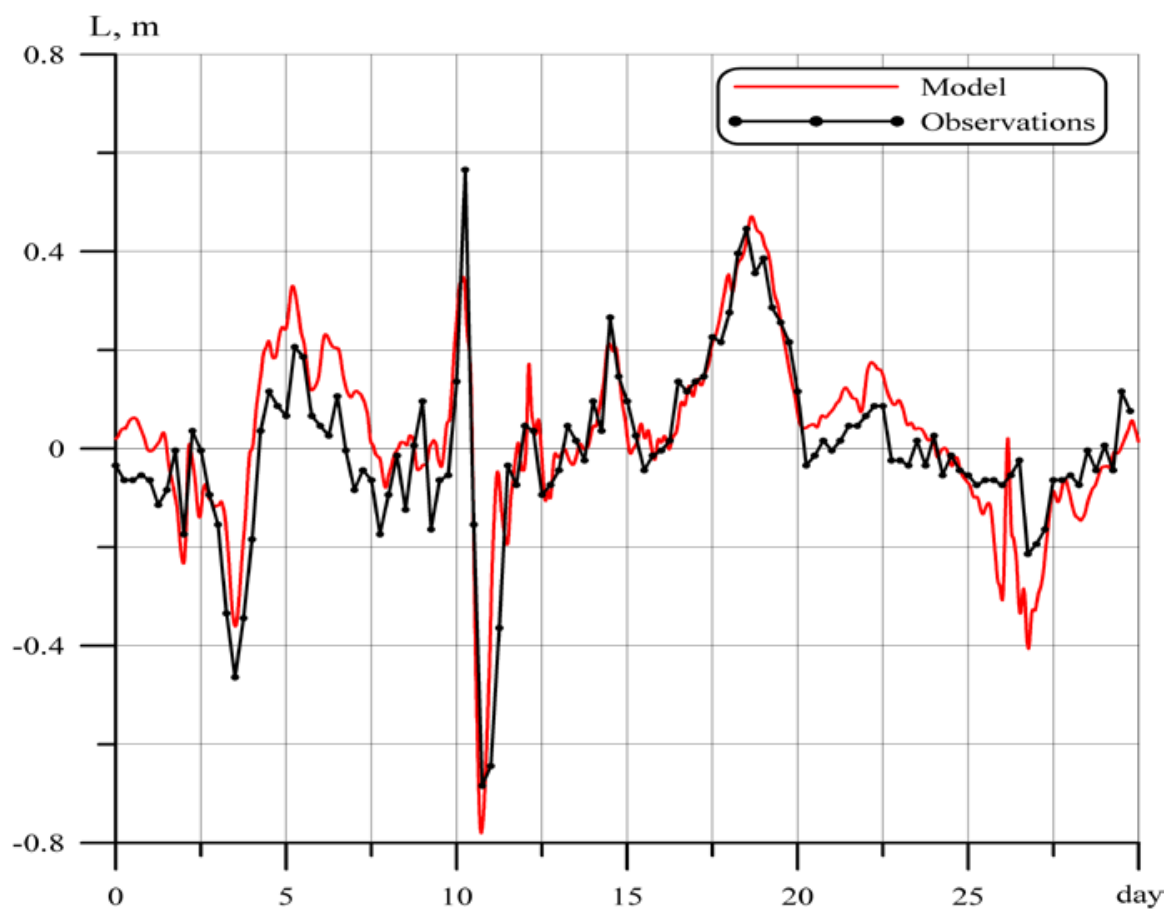

Fig. 5. The Azov Sea level (m) variations at HMS Mysovoe in November 2007

As you can see, the model adequately describes the variation in sea level. There is a satisfactory reproduction of level buildups and decay phases. At the same time mean square errors of the level calculation are about $7.5 \mathrm{~cm}$.

Propagation peculiarities of the river waters in the Azov Sea under calmwind conditions. River discharge is one of the main factors determining the thermohaline structure of the Azov Sea waters. Its inflow into the sea usually leads to the formation of the frontal zone salinity in estuarine areas.

Several articles (see [1,7], including the review in [8]) cover the research of the river water propagation in the sea basins based on the expeditionary data simulation and analysis.

Generally this process can be characterized as follows. The flow_of river water downstream first spreads towards the sea, and then under the influence of the Coriolis force turns to the right (in the Northern Hemisphere), and extends along the coast in the form of the jet stream. Meanwhile the characteristic bulge (plume) usually appears near the estuaries, which may include vortex structure between the main jet stream and the coast.

To reproduce the aforementioned mechanism we carried out the numerical experiment without taking into account the weather effects, i.e. the hypothetical conditions of complete calm $\left(\tau_{\alpha}^{0}=0\right)$ and zero heat and salt fluxes in the basin boundaries were set. The river discharge $Q_{r}$ was the only forcing, meanwhile the Don and Kuban discharges (accounting for nearly 98\% of all fresh water flows into the sea [2]) were set. 
The river water propagation within the Azov Sea water area under calm-wind conditions from one branch of the Don (R1 in Fig. 1) and two branches of the Kuban - the Kuban and the Protok (R2 and R3 in Fig. 1) was simulated. $Q_{r}$ are the mean annual values of the river discharge: $700 \mathrm{~m}^{3} / \mathrm{s}$ - the Don River; $170 \mathrm{~m}^{3} / \mathrm{s}$ the Kuban branch; $170 \mathrm{~m}^{3} / \mathrm{s}$ - the Protok branch. Water salinity at the river outlets was set equal to $2 \%$.

The horizontal turbulent viscosity and diffusion were not taken into account $\left(A_{m}=A_{c}=0\right)$. Model integration time was 365 days. Initially, the temperature and salinity were set constant over the entire water area $\left(T=14.7^{\circ} \mathrm{C}, S=13.7 \%\right.$ o $)$.
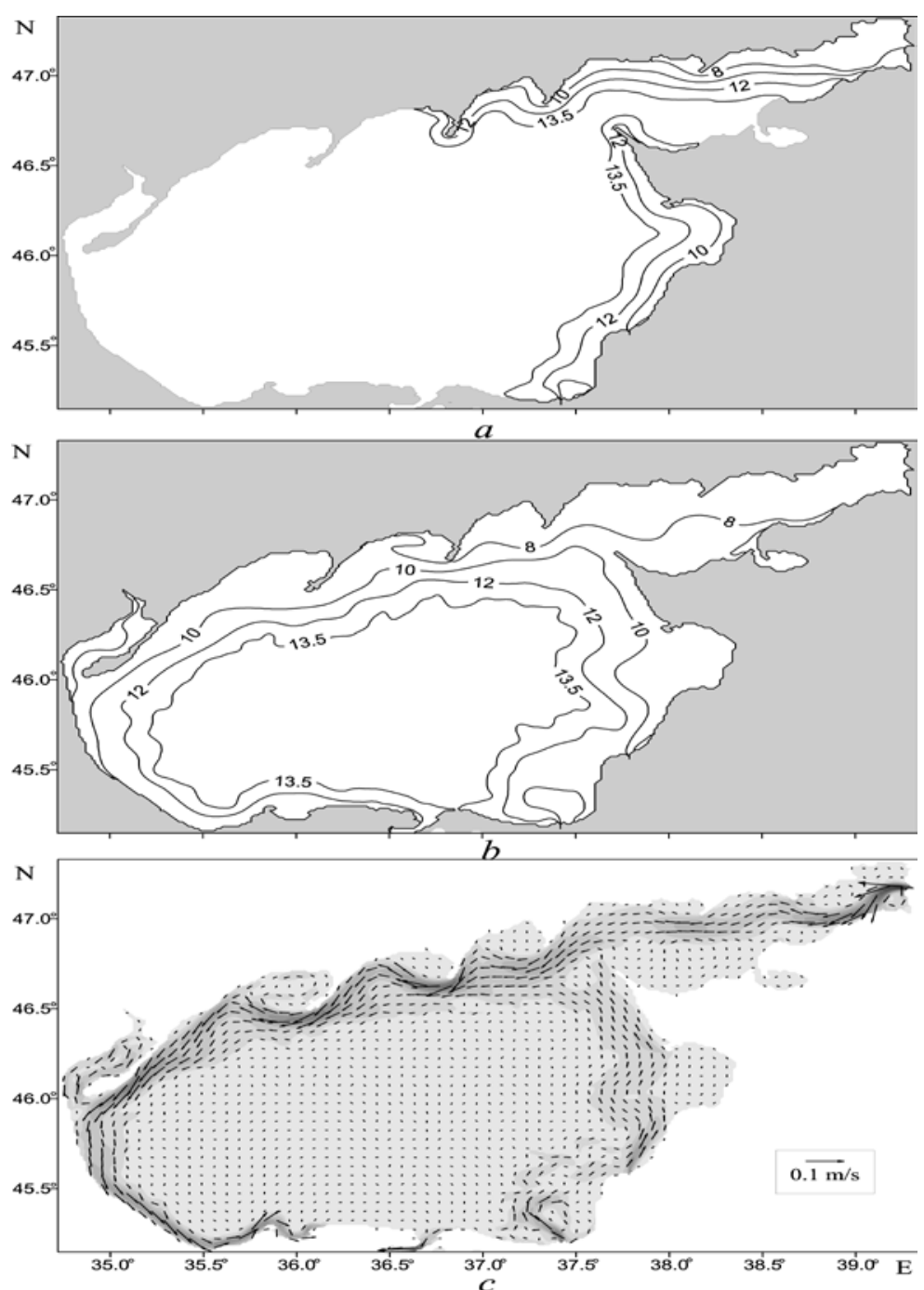

Fig. 6. Salinity fields, \%o $(a, b)$ and velocity of currents, $\mathrm{m} / \mathrm{s}(c)$ in the Azov Sea surface layer: $a-$ $t=0$ day; $b-t=72$ days; $c-t=245$ days

Fig. 6, $a, b$ shows the Azov Sea water salinity fields at the horizon $z=-1 \mathrm{~m}$ for specific time points 0 and 72 days. Position of the isolines 13.5; $12 ; 10$ and $8 \%$ o is demonstrated. The fields were obtained by means of linear interpolation with $\sigma$ PHYSICAL OCEANOGRAPHY NO. 1 (2015) 
grid on a $z$-coordinate one. As it can be seen, the Don fresh water jet travels along the north coast of the sea to the west, and the jets of the Kuban and the Protok branches - along the east coast to the north.

In due course, the jet of desalinated waters surrounds the entire coastal zone. The thickness of the jets is $1-1.5$ meters. The Kuban waters move along Dolzhanskaya Spit and enter the Taganrog Bay, mixing with the Don waters and forming the total stream. Further, this jet skirts the northern coast of the Crimea and penetrates into the Kerch Strait.

It is of interest to consider the main features of discharge currents appearing in the sea. An example of field of discharge currents for $z=-1$ and 245 days of integration is shown in Fig. 6, $c$.

It can be seen that the discharge currents are a cyclonic alongshore jet, encircling the sea and flowing into the Kerch Strait. The average velocity of currents in the jet is $0.03-0.05 \mathrm{~m} / \mathrm{s}$. Intensification of the discharge currents occur near capes and spit peaks. The highest velocities of the discharge currents $(0.1-$ $0.17 \mathrm{~m} / \mathrm{s}$ ) are observed near the estuaries of rivers.

The complexity of the coastline and bottom topography configuration leads to a jet meandering and formation of local vortex structures. Thus, a local cyclonic vortex is formed in the top of the Taganrog Bay to the left of the main jet. Near the Kuban estuary the plume can be traced in the classic form - the anticyclonic vortex is adjacent to the Kuban branch jet. Approaching Obitochnaya Spit, the jet bifurcates, forming a meander in the bay with a closed cyclonic circulation formed in its center. A similar picture of the jet bifurcation is even more clearly visible in the Utlyuksky estuary.

Thus, the results of numerical experiments show that the propagation character of river waters in the Azov Sea is consistent with the known theoretical concepts. We can assume that the mechanism, providing a fresh water flow from the Azov Sea to the Black Sea and their propagation westward along the Crimean coast, occurs under calm and light conditions.

The Azov Sea water dynamics in November 2007. The second numerical experiment was carried out to reproduce the dynamic response of the Azov Sea fields to the real storm situation. We chose November 2007 as the base period. This is due to the fact that during November $10-11$ in the Azov-Black Sea basin there was a powerful storm, which led to the catastrophe, when several ships in the Kerch Strait were damaged and the Azov Sea water level in the Berdyansk area became extremely high.

To estimate the heat and salt fluxes in the expressions (7) the climatic forcing method (relaxation towards climatology) was applied [9], whereby

$$
Q_{T}=\rho_{0} c_{p} \gamma_{T}\left(T_{\mathrm{cl}}-T\right), \quad Q_{S}=\rho_{0} \gamma_{S}\left(S_{\mathrm{cl}}-S\right),
$$

where $\gamma_{T}, \gamma_{S}$ are the set relaxation constants; $T_{\mathrm{cl}}, S_{\mathrm{cl}}$ are the climatic temperature and salinity at the sea surface; $T, S$ are the temperature and salinity values on the $1^{\text {st }}$ vertical $\sigma$-level.

The simulation was performed in two stages. On the first (auxiliary) stage (30 day time period) the initialization of the numerical model was carried out. The 
initial 3-dimensional temperature and salinity distributions of the Azov Sea water were obtained by interpolating the climatic fields from a database of observations of the Maritime Branch of the Ukrainian Hydrometeorological Institute. Horizontally the interpolation was applied with weights inversely proportional to the distance to the node based on the correlation radius [2]. Vertically the linear interpolation with monotony control of temperature and salinity profiles was used. Zero values were set for the velocity of currents and sea level at the initial time. The contribution of wind and atmospheric pressure at this stage was not considered ( $\tau_{\alpha}^{0}=0, p_{a}=0$ ). Horizontal eddy viscosity coefficient $A_{m}$ was calculated using the Smagorinsky formula [3], and the coefficient of horizontal turbulent diffusion temperature and salinity was $A_{c}=0.2 A_{m}$ [6].

Obtained after 30 day integration, fields of currents, sea level, temperature and salinity were taken as the initial conditions for the second stage. At this stage (November, 1 - 30, 2007), calculation of the effect of wind and atmospheric pressure was performed. Surface tangential wind stress and atmospheric pressure gradients were calculated on the basis of SKIRON mesoscale model data (http://forecast.uoa.gr) for November 2007. Spatial resolution of the meteorological fields over the Azov Sea was $10 \mathrm{~km}$, and the time discretion was 2 hours.

At both simulation stages climatological forcing and river discharge was taken into account. To calculate the river discharges and fields $T_{\mathrm{cl}}, S_{\mathrm{cl}}$ in the expressions in (12) the climate data time interpolation for October - November was used. By analogy with [9], the relaxation constants in (12) took the following values: $\gamma_{T}=2.315 \cdot 10^{-5} \mathrm{~m} / \mathrm{s}, \gamma_{S}=2.315 \cdot 10^{-4} \mathrm{~m} / \mathrm{s}$.

According to the numerical simulation results, the intense wind-induced sea level fluctuations periodically occurred in the sea due to wind increase. These fluctuations were the time alternating raising level fields at the windward coasts and the lowering level ones - at the leeward coasts. During periods of relative calm in the central part of the sea a cyclonic phase shift of oscillations was traced, i.e. in the course of time, there was a counterclockwise rotation of raising and lowering level areas round the basin center by analogy with Kelvin waves in a closed basin. As shown in [3], this character of oscillation phase changes is caused by the Coriolis force.

During the simulated period, the most significant positive surges (over $1 \mathrm{~m}$ ) occurred: on the west side of Obitochnaya Spit; at the peak of the Taganrog Bay; on the south side of Dolgaya Spit; in the Yasenskoy Bay coastal area. Negative surges most clearly manifested themselves along the west coast of the sea (Arabatskaya Spit area) and in the eastern part of the Taganrog Bay.

In accordance with the analysis of the current simulation results, for the period from 1 to 30 November 2007, there was the episodic intensification of currents due to wind amplification during the storms. When the wind weakened, the relative contribution of the drift component decreased and the role of compensation currents increased.

Significant speed and direction variability of the wind field contributed to the constant restructuring of the circulation. This prevented the formation of any longlived vortex structures and countercurrents, like the ones that occurred in the sea under stationary wind conditions [2, 3].

PHYSICAL OCEANOGRAPHY NO. 1 (2015) 
The general trend is the intensification of currents at the extremities of the spits and in the narrownesses. The most dynamically active region is the western part of the Taganrog Bay, due to the presence of strong reverse currents during the abrupt change in wind direction. Attention is drawn to the local topographic effect, i.e. intensification of the currents over the Zhelezinskaya Bank.
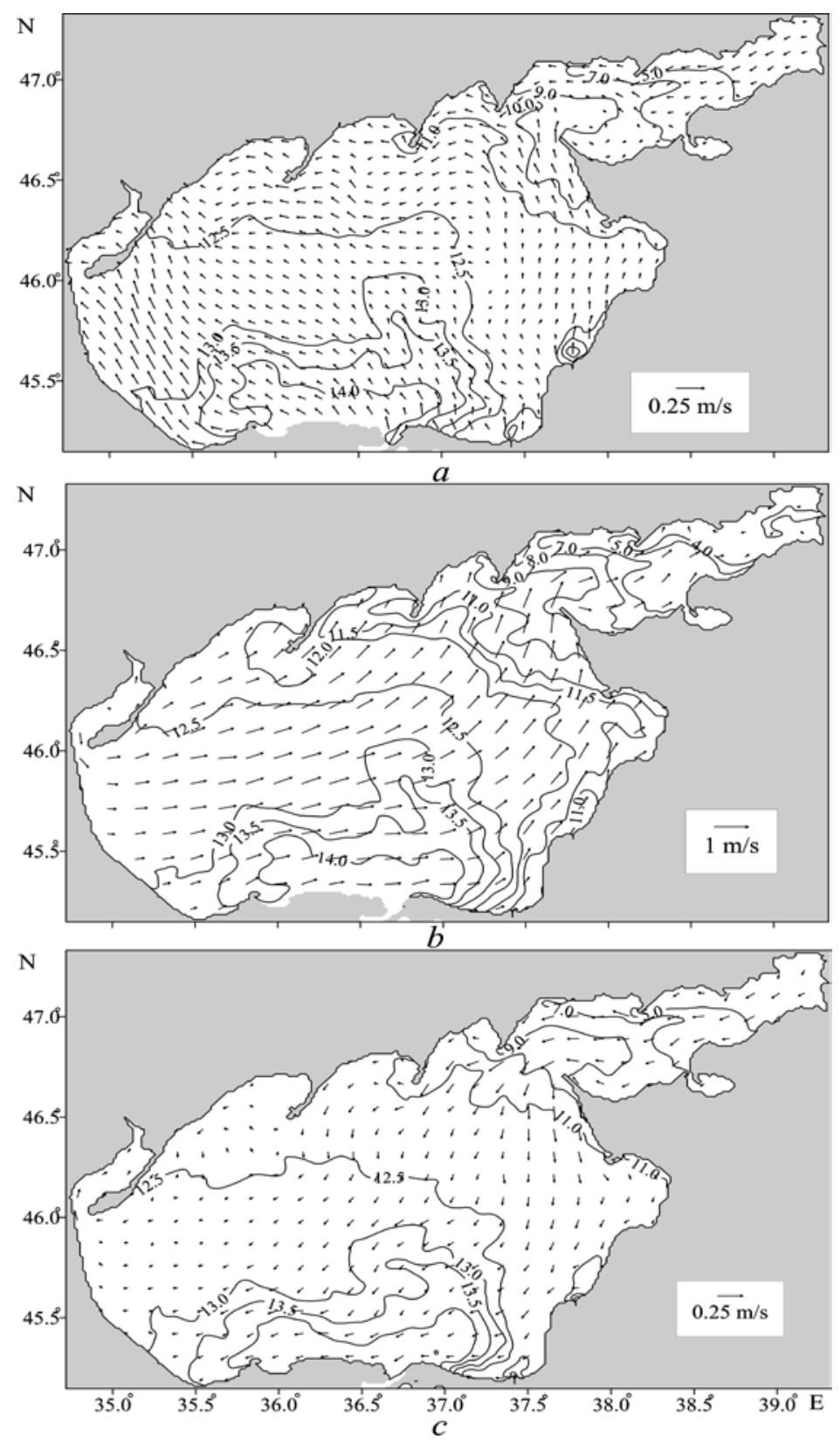

Fig. 7. Fields of salinity (\%) and velocity of currents (m/s) in the Azov Sea surface layer: $a-10$ November, 10, 2007, 12:00 GMT; $b$ - November, 11, 2007, 12:00 GMT; $c$ - November, 17, 2007, 12:00 GMT 
Fields of salinity and velocity of currents of the Azov Sea in the surface layer (on the horizon $z=-1 \mathrm{~m}$ ) for three specific time moments (the day before the storm on November, 11, the storm period and a week after the storm) are shown in Fig. 7. As it can be seen, the salinity distribution in the central part of the sea is the most homogeneous. We can clearly identify several areas with high salinity gradient: frontal zone in the Taganrog Bay, determined by the Don discharge; high salinity area in the southern part of the sea tied with the Black Sea water penetration through the Kerch Strait with winds of southern bearings; two local desalinated water zones near the Kuban branches.

There are horizontal shifts of the frontal salinity zones under strong winds. So, in the Taganrog Bay frontal zone the salinity variations reach $2-3 \%$. On the contrary, in the deep-sea hollow, these variations do not exceed $0.2 \%$. During the storm periods, there is a significant reduction in the size of the plume near the Kuban branches (until their complete disappearance). In the periods of relative calm the plumes start to manifest themselves again. Generally, trends in salinity changes in certain areas of the sea are determined by the fact, whether the current wind is of negative or positive surge relating to the area under consideration. In accordance with the analysis of the vertical structure of temperature and salinity fields, in $1.5-2$ days after the start of the strong wind action the extensive complete vertical mixing of water masses begins.

Conclusions. A simulation of the propagation of the Don and Kuban waters in the Azov Sea without taking into account external influences was performed. It was found that the discharge currents became an alongshore jet with cyclonic direction, encircling the Azov Sea. Velocity of the currents in the jet was $0.03-$ $0.05 \mathrm{~m} / \mathrm{s}$. Intensification of the discharge currents occured near capes and peaks of the spits. They reached their maximum velocities $(0.1-0.17 \mathrm{~m} / \mathrm{s})$ near the estuaries of rivers. The complexity of the coastline configuration and bottom topography heterogeneity led to meandering of the jet of the discharge currents and appearance of local vortex formations.

The numerical simulation of the evolution of currents and thermohaline structure of the Azov Sea water under intensive wind effects was carried out. As the initial fields, the Azov Sea water temperature and salinity climatic distributions were used, as the forcing - the results of atmospheric field numerical simulation for November 2007.

It was shown that the most dynamically active areas are: frontal zone in the Taganrog Bay, determined by the Don discharge; high salinity area in the southern part of the sea tied with the Black Sea water penetration through the Kerch Strait with winds of southern bearings; two local desalinated water zones near the Kuban branches. On the contrary, in the deep-sea hollow, these variations did not exceed $0.2 \%$. In $1.5-2$ days after the start of the strong wind action, the extensive complete vertical mixing of water masses began.

Acknowledgements. The research was carried out under the support of the Project Developing of the methods and building of the experimental sample biotechnical monitoring system of the shelf zones of the seas of the Western Arctic 
and the South of Russia, including the area of the Crimean peninsula, on the basis of satellite and contact data (code 2014-14-579-0115-020, RFMEFI60714X0059).

\section{REFERENCES}

1. Fomin, V.V., 2006, "Primenenie TVD-skhem dlya chislennogo modelirovaniya frontal'nykh zon solenosti $v$ melkom more [The use of TVD-schemes for numerical modeling of the frontal zones of salinity in the shallow sea]”, Meteorologiya i gidrologiya, no. 2, pp. 59-68 (in Russsian).

2. Il'in, Yu.P., Fomin, V.V., \& D'yakov, N.N. [et al.], 2009 “Gidrometeorologicheskie usloviya morey Ukrainy. T. 1. Azovskoe more [Hydrometeorological conditions of the Ukraine seas]", Sevastopol, ECOSI-Gidrofizika, vol. 1, p. 401 (in Russian).

3. Ivanov, V.A., Fomin, V.V. 2010, "Matematicheskoe modelirovanie dinamicheskikh protsessov $v$ zone more - susha [Mathematical Modelling of Dynamical Processes in the Sea-Land Area]”, Sevastopol, ECOSI-Gidrofizika, p. 363 (in Russian).

4. $\quad$ Fomin, V.V., 2002, "Chislennaya model' tsirkulyatsii vod Azovskogo morya [A numerical water circulation model in the Sea of Azov]”, Nauch. tr. Ukr. nauchno-issled. gidrometeorol. in-ta, no. 249, pp. 246-255 (in Russian).

5. Harten, A., 1984, "On a class of high resolution total-variation-stable finite-difference schemes”, Society for Industrial and Applied Mathematics, vol. 21, no. 1, pp. 1-23.

6. Blumberg, A.F., Mellor, G.L., 1987, "A description of three-dimensional coastal ocean circulation model”, Three-Dimensional Coast Ocean Models, vol. 4, pp. 1-16.

7. Mikhailova, E.N., Shapiro, N.B., 1996, "Modelirovanie rasprostraneniya i transformatsii rechnykh vod na severo-zapadnom shel'fe $i v$ glubokovodnoy chasti Chernogo morya [Modeling of distribution and transformation of river waters on the northwestern shelf and in deep-sea part of the Black Sea]", Morskoy gidrofizicheskiy zhurnal, no. 3, pp. 30-40 (in Russian).

8. $\quad$ Fong, D.A., Geyer, W.R. 2002, "The alongshore transport of freshwater in a surface-trapped river plume”, J. Phys. Oceanogr., vol. 32, no. 3, pp. 957-972.

9. Jankowski, A. 2002, "Application of the $\sigma$-coordinate baroclinic model to the Baltic Sea", Oceanologia, no. 44 (1), pp. 59-80. 